\title{
Influence of Pod Stomatal Density and Pod Transpiration on the Calcium Concentration of Snap Bean Pods
}

\author{
Michael A. Grusak ${ }^{1}$ and Kirk W. Pomper ${ }^{2}$ \\ U.S. Department of Agriculture, Agricultural Research Service, Children's Nutrition Research Center, \\ Department of Pediatrics, Baylor College of Medicine, 1100 Bates Street, Houston, TX 77030-2600
}

\begin{abstract}
ADDITIONAL INDEX WORDS. nutrition, minerals, mineral requirements, green beans, vegetables, human nutrition, bioavailability, health, postharvest, Phaseolus vulgaris

ABSTRaCt. Understanding the mechanisms that regulate xylem transport of calcium (Ca) to snap bean (Phaseolus vulgaris L.) pods could allow approaches to enhance pod Ca levels, and thereby improve the value of this food source for humans. Pods of greenhouse-grown plants of 'Hystyle', 'Labrador', 'Tendergreen', 'Green Crop', 'BBL94', and 'Gold Crop' were examined for stomatal density and rates of pod transpiration throughout pod development. Among pods ranging from 6 to $14 \mathrm{~mm}$ in diameter, Ca concentration and pod stomatal density varied inversely with increasing diameter in all cultivars; Ca concentration for pods of a given diameter also varied among cultivars. To assess the influence of pod stomatal density on pod transpiration, water loss was measured from detached pods of 'Hystyle' and 'Labrador', which have high and low pod stomatal densities, respectively. Pod transpiration rates were similar for the two cultivars, being $\approx 15 \%$ the rate measured in leaves under equivalent conditions, and comparable to rates of cuticular transpiration measured in leaves with closed stomates. These results suggest that pod stomates have no role, or have only a limited role, in pod transpiration. Pods of 'Hystyle' and 'Labrador' were placed in enclosures that maintained constant high- or low-humidity environments throughout pod development. For each cultivar, the high-humidity environment led to lower pod Ca concentrations, demonstrating that pod transpiration does have a significant impact on pod Ca accretion. However, 'Hystyle' consistently exhibited higher pod Ca concentrations, relative to 'Labrador', suggesting that differences in xylem sap Ca concentration may have been responsible for cultivar differences in pod Ca concentration.
\end{abstract}

Snap beans (Phaseolus vulgaris) are a commonly consumed vegetable that can provide several essential nutrients in the human diet. Relative to other fruits and vegetables, snap beans contain a high concentration of $\mathrm{Ca}$, with a mean value of $\approx 5 \mathrm{mg} \cdot \mathrm{g}^{-1}$ dry mass (Quintana et al., 1996; U.S. Dept. of Agriculture, 1984). This Ca is present in a highly available form, as evidenced by studies in teenagers, which demonstrated that $\mathrm{Ca}$ absorption from snap beans was comparable to that from milk (Abrams et al., 1997). The potential for developing new snap bean cultivars with enhanced pod $\mathrm{Ca}$ concentration has been investigated recently at the genetic (Quintana et al., 1996) and physiological (Grusak et al., 1996) levels.

Processes regulating the accretion of $\mathrm{Ca}$ in developing snap bean pods are poorly understood. Recently, it was demonstrated that differences in pod $\mathrm{Ca}$ concentration between two snap bean cultivars were not due to differences in net $\mathrm{Ca}$ influx via the roots, but rather were due to differences in partitioning of $\mathrm{Ca}$ to the pods (Grusak et al., 1996). Calcium is thought to enter pods almost exclusively via the xylem pathway, because only trace amounts of $\mathrm{Ca}$ are transported in the phloem system (Raven, 1977). This movement of Ca-containing xylem fluid into a pod is dependent on two processes: growthinduced water influx (Cosgrove, 1986; Nonami and Boyer, 1987) and pod transpiration (Mix and Marschner, 1976a, 1976b). The relative

Received for publication 19 June 1998. Accepted for publication 13 Nov. 1998. We acknowledge the technical assistance of Kevin Koch and Jean Sunega, and thank LI-COR, Inc. for the loan of a porometer. This project has been funded in part with federal funds from the USDA-ARS under Cooperative Agreement 58-6250-6-001. The contents of this publication do not necessarily reflect the views or policies of the USDA, nor does mention of trade names, commercial products, or organizations imply endorsement by the U.S. Government. The cost of publishing this paper was defrayed in part by the payment of page charges. Under postal regulations, this paper therefore must be hereby marked advertisement solely to indicate this fact. ${ }^{1}$ To whom reprint requests should be addressed.

${ }^{2}$ Current address: Principal Investigator of Horticulture, Curator of the USDA National Clonal Germplasm Repository for Asimina sp., Kentucky State University, Atwood Research Facility, Frankfort, KY 40601. contribution of either process to total pod water balance, or Ca import, has not been determined. In fruiting organs of other species, low rates of transpiration have been reported, which can lead to reduced rates of $\mathrm{Ca}$ accretion into these organs (Clarkson, 1984; Ehret and Ho, 1986; Faust and Shear, 1968; Hanger, 1979; Shear, 1975).

Information relevant to the transpiration capacity of legume pods is limited. Stomates are present in the epidermis of snap bean pods and pods can fix atmospheric carbon dioxide (Crookston et al., 1974); these findings suggest that pod stomates may contribute to wholeorgan gas exchange. Stomatal density of pods was reported to be only $25 \%$ of that of the snap bean lower leaf surface (Crookston et al., 1974); therefore, transpiration would likely be lower in pods than in leaves of snap bean. However, little is known about the functional capability of pod stomates, and it is possible that the waxy cuticle covering the pod epidermis may be the predominant factor influencing water loss (i.e., nonstomatal or cuticular transpiration) (Kerstiens, 1996).

Because we are interested in enhancing the Ca nutritional quality of snap beans for human consumption, we have investigated factors related to pod water balance that might explain the reported cultivar variations in pod Ca concentration (Grusak et al., 1996; Quintana et al., 1996). We have measured pod stomatal density, pod Ca concentration, and rates of pod transpiration throughout pod development. The influence of canopy microclimate on pod $\mathrm{Ca}$ concentration also was examined by maintaining pods under equivalent microclimate conditions. Comparisons between cultivars will be used to discuss the role of these water relations factors on the Ca nutrition of developing snap bean pods.

\section{Materials and Methods}

Plant material and growth Conditions. Six snap bean cultivars (Hystyle, Labrador, Tendergreen, Green Crop, Gold Crop, and BBL94) were grown in a greenhouse with supplemental lighting and 
temperature control. Environmental conditions for the plants were a temperature regime of $24 \pm 3{ }^{\circ} \mathrm{C}$, day and $20 \pm 3{ }^{\circ} \mathrm{C}$, night, with relative humidity $(\mathrm{RH})$ ranging from $45 \%$ to $65 \%$ throughout the day/ night cycle. Sunlight was supplemented with metal halide lamps; the lamps ensured a 14-h day, 10-h night photoperiod (lights on at $800 \mathrm{~h}$ ), and a minimum PPF of $200 \mu \mathrm{mol} \cdot \mathrm{m}^{-2} \cdot \mathrm{s}^{-1}$ at the top of the plants. Plants were grown one plant per 1.5-L pot in a synthetic soil mix (Metro-Mix 360; Scotts-Sierra Horticultural Products Co., Marysville, Ohio); pots were spaced $\approx 0.4 \mathrm{~m}$ apart. All cultivars were grown at the same time and plants were randomly assigned positions on the greenhouse benches. Plants were watered twice daily with $100 \mathrm{~mL}$ of a nutrient solution containing: $3 \mathrm{~mm} \mathrm{KNO}_{3}, 0.275 \mathrm{~mm} \mathrm{CaCl}_{2}, 0.25 \mathrm{~mm} \mathrm{MgSO}_{4}$, and $0.25 \mathrm{mM} \mathrm{KH}_{2} \mathrm{PO}_{4}$.

Stomatal DENSITY. Pods of various size were excised from plants (a minimum of 12 plants per cultivar) in order to determine the density of stomates in the region of each pod's widest diameter. Calipers were used to measure pod diameter to the nearest $0.1 \mathrm{~mm}$. Once a site was measured, a thin layer of fingernail polish (Sally Hanson; Hard as Nails, Farmingdale, N.Y.) was applied to an area of $\approx 2 \mathrm{~cm}^{2}$ on both sides of the pod, between the dorsal and ventral pod sutures. After drying (10 to $12 \mathrm{~min}$ ), each area of polish was carefully peeled off the pod and was placed on a glass microscope slide, pod side up, and was covered with a glass coverslip. Pods smaller than $5 \mathrm{~mm}$ in diameter were avoided in this analysis, because they produced torn or stretched epidermal peels.

Pod surface peels were viewed with a compound microscope (Optiphoto-2; Nikon Microscopes, Melville, N.Y.) to measure stomatal density. The field of view was delineated by a square inscribed on one of the eyepiece lenses; dimensions of the area defined by the square at each magnification were determined using a stage micrometer. Magnification was adjusted so that 25 to 60 stomates were counted per field (field of views ranged from 29 to $56 \mu \mathrm{m}^{2}$ ). Only those stomates whose guard cells were completely within the field of view were counted. Counts were made at five randomly chosen locations on each of the two peels from each pod. The 10 counts were used to calculate a mean value for each pod; coefficients of variation were typically $<5 \%$.

Pod Ca concentrations. Pods harvested for stomatal density measurements were subsequently analyzed for $\mathrm{Ca}$ concentration. Pods were dried at $70^{\circ} \mathrm{C}$ until a constant mass was attained. Entire pods were wet digested and the digestate resuspended as described in Grusak (1994). Total Ca content per gram dry mass of pod was determined using atomic absorption spectrophotometry (AAS) (model 2100; Perkin Elmer, Norwalk, Conn.).

Pod water loss. Water loss from excised pods was used as a proxy for in vivo transpiration rates ('Hystyle' and 'Labrador' only). Water loss was determined by measuring the change in pod fresh mass over a 1 -h period with an electronic balance $(0.1 \mathrm{mg}$ resolution; model PM480; Mettler-Toledo, Hightstown, N.J.). Preliminary studies in which pods were weighed at 15-min intervals demonstrated that water loss rates were constant for up to $2 \mathrm{~h}$. Environmental controls for water loss measurements were: $23 \pm 1^{\circ} \mathrm{C}$ (mean $\left.\pm \mathrm{SD}\right)$ and a $\mathrm{RH}$ of $55 \% \pm 4 \%$.

Pod water loss was measured either with minimal illumination (a $\mathrm{PPF}$ of $40 \mu \mathrm{mol} \cdot \mathrm{m}^{-2} \cdot \mathrm{s}^{-1}$ was provided by fluorescent lamps) or in darkness. For illuminated pods, plants were brought into the laboratory between 1300 and $1330 \mathrm{HR}$. After a 30-min period of adjustment, pods were excised from the plant by cutting the peduncle near the basal end of the pod and were weighed twice over a 1-h interval. The cut end of the pod was not covered, because preliminary experiments (+/- lanolin application to the cut surface) demonstrated that water loss from the cut peduncle ( $\leq 1 \mathrm{~mm}$ in diameter) was negligible to nonexistent. For pods measured in darkness, plants were brought into the laboratory at $1800 \mathrm{HR}$ the day before the study, and all room lights were turned off. At $0400 \mathrm{HR}$ the next morning, pods were excised and weighed twice over a 1-h interval, as described.

After the two weighings, pods were stored in a refrigerator at $4{ }^{\circ} \mathrm{C}$ until their length and width could be measured later that day. Length was measured to the nearest $0.5 \mathrm{~mm}$ and was chosen to be the distance from the basal end, up to the base of the narrow tip (i.e., the remnant tissue of the floral stigmatic projection) at the apical end of the pod. Width was determined at the pod's widest diameter. Pod surface area was calculated as surface area $=\pi \mathrm{LD}$, where $\mathrm{L}$ is length and $\mathrm{D}$ is diameter as described above, because pods approximated a cylinder with a circular cross-sectional profile.

TransPiration. Pod and leaf transpiration rates for attached organs, along with temperature and relative humidity, were measured with a steady-state porometer (LI-1600; LI-COR, Lincoln, Neb.) using a model 1600-07 cylindrical chamber (aperture set at $1 \mathrm{~cm}^{2}$ ) as described by the manufacturer. Whole pods were placed in the chamber, which meant that pods of $<3.5 \mathrm{~cm}$ in length or only 2 to 2.5 $\mathrm{mm}$ in diameter could be measured. Measurements were taken during midafternoon in the greenhouse on at least six pods and four leaves each from 'Hystyle' or 'Labrador' on 6 days. Pod surface area was calculated as described in the previous section, and transpiration rates were calculated for pods based on total surface area; leaf transpiration rates were calculated for a single (abaxial) surface.

Pod microclimate Treatments. To test whether differences in pod microclimate could influence pod $\mathrm{Ca}$ concentration, pods on intact plants of 'Hystyle' and 'Labrador' were placed in specially designed chambers to provide regulated $\mathrm{RH}$ and temperature environments. Briefly, emerging pods on the top most raceme (at $35 \mathrm{~d}$ after planting) were placed in plastic chambers (4-L clear plastic bottles), which contained small fans (Brushless D.C. Blower; catalog no. 273-260, Radio Shack Corp., Fort Worth, Tex.) to provide air mixing. The chambers were covered with aluminum foil. The leaf subtending the raceme was severed prior to placement of the raceme in the chamber. Each chamber was supplied with a stream of air (Maxima Air Pump, Rolf C. Hagen Corp., Mansfield, Mass.) that provided a pod environment that was either: 1) a high-RH environment, where air was saturated with water vapor by bubbling the air through distilled water in a 5-L flask (during the day this flask was maintained in a $40{ }^{\circ} \mathrm{C}$ water bath), or 2) a low-RH environment, where air was run through columns of calcium sulfate desiccant (Drierite; W.A. Hammond Drierite Comp. LTD, Xenia, Ohio) to remove water vapor. In both treatments, $\approx 0.7 \mathrm{~L} \mathrm{~min}^{-1}$ of air was delivered to each chamber. $\mathrm{RH}$ and temperature were measured continuously using RH HOBO and TEMP HOBO sensors (Onset Computer Corp., Pocasset, Mass.). Twelve plants of each cultivar were fitted with chambers over the pods of the top-most raceme; six chambers each were provided air at either a high or low RH. In six control plants, the leaf subtending the top-most raceme was severed on each plant at $35 \mathrm{~d}$, but pods were not enclosed in plastic containers. Fifteen days later, mature pods from the high-RH treatment, the lowRH treatment, and control plants were collected for the determination of pod $\mathrm{Ca}$ concentration as described above.

Statistical ANALYSIS. Linear or polynomial regressions were performed on data sets using Microsoft Excel version 5.0 software (Microsoft, Seattle, Wash.). Data for pod or leaf transpiration rates were analyzed using a paired student $t$ test with Statview software (Abacus Concepts, Berkeley, Calif.). Data for pod transpiration rates and for the $\mathrm{Ca}$ concentration of pods that developed in a high-RH, low-RH, or ambient greenhouse environment were subjected to analysis of variance using Costat (CoHort Software, Minneapolis, Minn.). Contrast analysis of treatment means was accomplished as described in the Costat manual. 

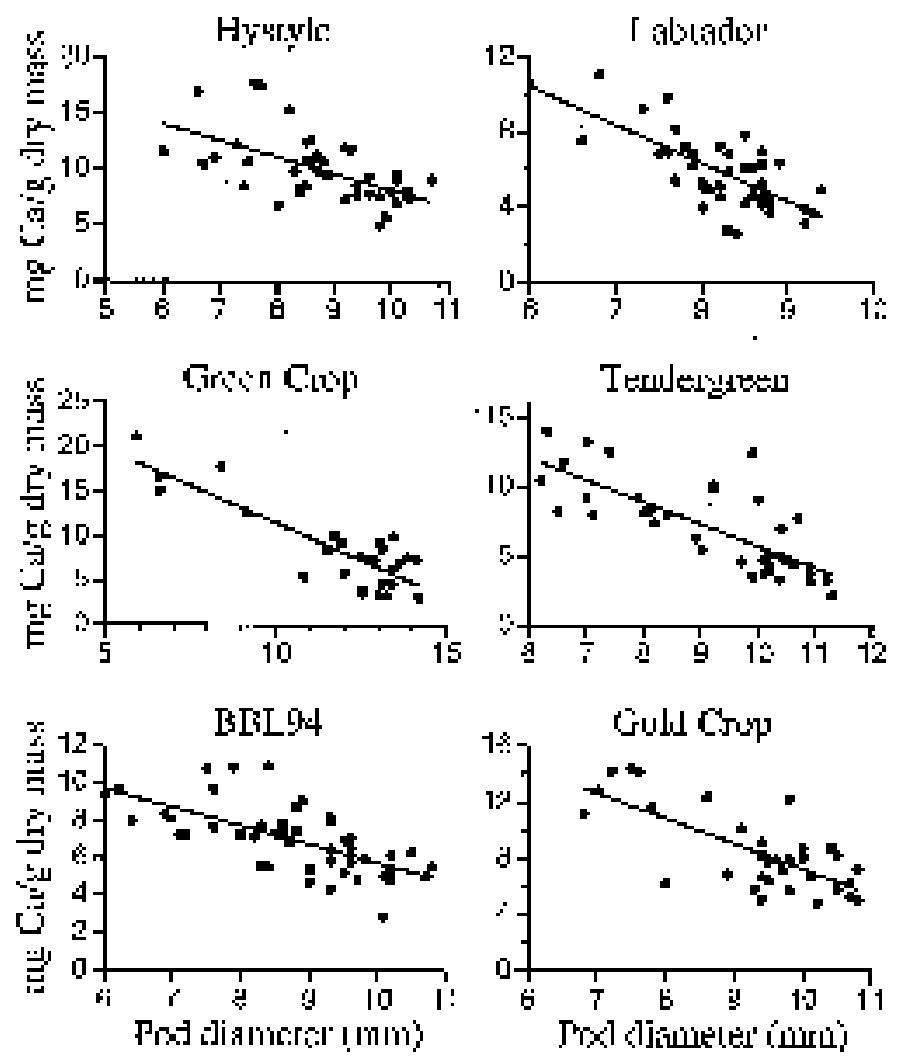

Fig. 1. Calcium concentrations (dry mass basis) measured in pods of various diameters for six snap bean cultivars. Plants were grown individually in pots in a greenhouse. Pod diameter was measured at each pod's widest diameter. The linear regression equation calculated for each data set was 'Hystyle', $\mathrm{y}=-1.47 \mathrm{x}$ $+22.79, r^{2}=0.33$; 'Labrador', $\mathrm{y}=-2.02 \mathrm{x}+22.52, r^{2}=0.52$; 'Green Crop', $\mathrm{y}=$ $-1.69 \mathrm{x}+28.29, r^{2}=0.73$; 'Tendergreen', $\mathrm{y}=-1.59 \mathrm{x}+21.57, r^{2}=0.59$; 'BBL94', $\mathrm{y}=-0.99 \mathrm{x}+15.60, r^{2}=0.44$; 'Gold Crop', $\mathrm{y}=-1.81 \mathrm{x}+25.28, r^{2}=0.53$

\section{Results}

Pod Ca CONCENTRation AND STOMatal Density. Calcium concentrations varied inversely with increasing pod diameter in all cultivars (Fig. 1). All relationships were statistically significant, with slopes $\left(\mathrm{Ca}\right.$ at $\left.\mathrm{mg} \cdot \mathrm{g}^{-1} \cdot \mathrm{mm}^{-1}\right)$ for the linear regressions varying from -0.99 ('BBL94') to -2.02 ('Labrador'). A test for homogeneity of slopes indicated significant differences between 'BBL94' and 'Labrador' $(P=0.003)$, 'Tendergreen' $(P=0.03)$, 'Green Crop' $(P=0.007)$, and 'Gold Crop' $(P=0.02)$.

As pod diameter increased, pod stomatal density declined in all cultivars investigated (Fig. 2). This inverse relationship was statistically significant in all cases $(P<0.01)$. The slopes (stomates $/ 100 \mu \mathrm{m}^{2} /$ $\mathrm{mm}$ ) for these relationships varied from -6.4 ('BBL94') to -14.9 ('Hystyle'). A test for homogeneity of slopes indicated significant differences between 'BBL94' and 'Hystyle' $(P=0.0001)$, 'Tendergreen' $(P=0.01)$, and 'Green Crop' $(P=0.02)$, between 'Tendergreen' and 'Labrador' $(P=0.01)$, 'Green Crop' $(P=0.02)$, and 'Gold Crop' $(P=0.0006)$, and between 'Labrador' and 'Hystyle' $(P=0.0008)$.

PoD TRANSPIRATION. Rates of water loss were not significantly different between 'Hystyle' and 'Labrador' when measurements were performed with pods either in light or in darkness (Fig. 3). However, in smaller pods of both cultivars (i.e., 3 to $4 \mathrm{~mm}$ diameter), measured rates of water loss were higher among pods in darkness ( $t$ test, $P=0.001$ ) (Fig. 3). Transpiration rates measured with a porometer in the light on attached whole pods ( 2 to $2.5 \mathrm{~mm}$ diameter) agreed with those of the water loss rates from detached pods. Pod transpiration rates for 'Hystyle' and 'Labrador' were not significantly different at $30.3 \pm 3.2$ (mean \pm SE) and $26.8 \pm 2.7$ $\mathrm{nmol} \cdot \mathrm{m}^{-2} \cdot \mathrm{s}^{-1}$, respectively. Subjecting the data to an analysis of variance showed nonsignificant effects for day of measurement $(P=$ $0.13)$ or cultivar type $(P=0.12)$ on pod transpiration rate, nor was there a significant interaction between day of measurement and cultivar main effects $(P=0.11)$. For these measurements, pod temperature $\left(24.7 \pm 0.2^{\circ} \mathrm{C}\right)($ mean $\pm \mathrm{SE})$ was consistent, while greenhouse $\mathrm{RH}(38.6 \% \pm 4.2 \%)$ varied slightly between days; however, these parameters were not different between the two cultivars on a given day. Leaf transpiration rates were the same in 'Hystyle' and 'Labrador'. The average leaf transpiration rate for the two cultivars was 203.4 \pm $23.2(\mathrm{SE}) \mathrm{nmol} \cdot \mathrm{m}^{-2} \cdot \mathrm{s}^{-1}$. By comparison, the transpiration rate for pods was only $14 \%$ the rate of leaves (abaxial surface only).

PoD microclimate Treatments. To assess the influence of pod microclimate on pod $\mathrm{Ca}$ concentration, developing pods were enclosed in chambers maintained at two levels of RH. Chamber environments were maintained at $100 \% \mathrm{RH}$ in the high-humidity treatment, and $\approx 15 \% \mathrm{RH}$ in the low-humidity treatment, over the course of pod development from 35 to $50 \mathrm{~d}$ after planting. Plants bearing control pods were subjected to a greenhouse environment that averaged $65 \%$ RH during the night and $45 \%$ RH during the day over the same developmental period. Temperatures in the chambers of high and low RH treatments were $\approx 1^{\circ} \mathrm{C}$ higher than the ambient greenhouse temperature during the day.

The mean Ca concentrations of pods that developed in a high- $\mathrm{RH}$, low-RH, or ambient environment are shown in Table 1. Subjecting
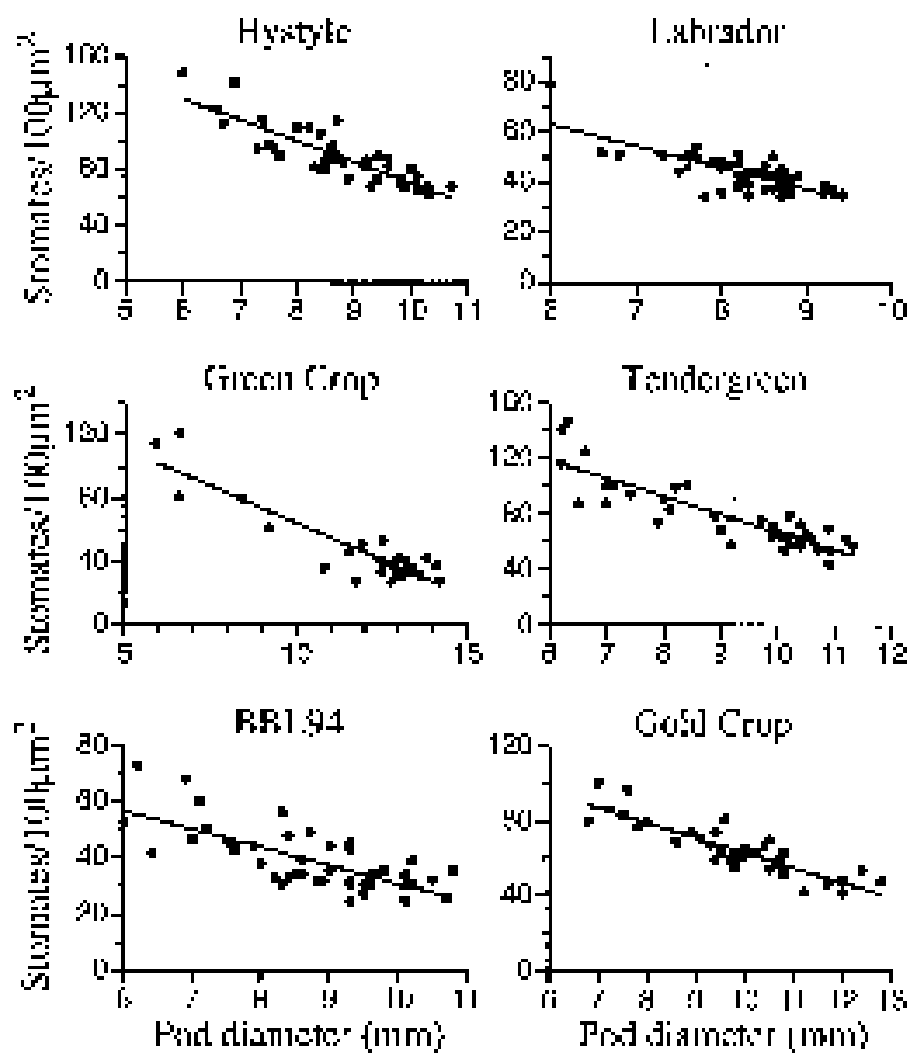

Fig. 2. Stomatal density measured in pods of various diameters for six snap bean cultivars. Plants were grown individually in pots in a greenhouse. Pod diameter was measured and stomatal density was determined at each pod's widest diameter. The linear regression equation calculated for each data set was 'Hystyle', $\mathrm{y}=-14.91 \mathrm{x}+219.31, r^{2}=0.72$; 'Labrador', $\mathrm{y}=-8.58 \mathrm{x}+114.42, r^{2}=$ 0.56; 'Green Crop', $\mathrm{y}=-9.32 \mathrm{x}+157.70, r^{2}=0.82$; 'Tendergreen', $\mathrm{y}=-12.95 \mathrm{x}$ $+196.61, r^{2}=0.76$; 'BBL94', $\mathrm{y}=-6.42 \mathrm{x}+95.16, r^{2}=0.53$; 'Gold Crop', $\mathrm{y}=-$ $7.97 \mathrm{x}+142.68, r^{2}=0.75$. 


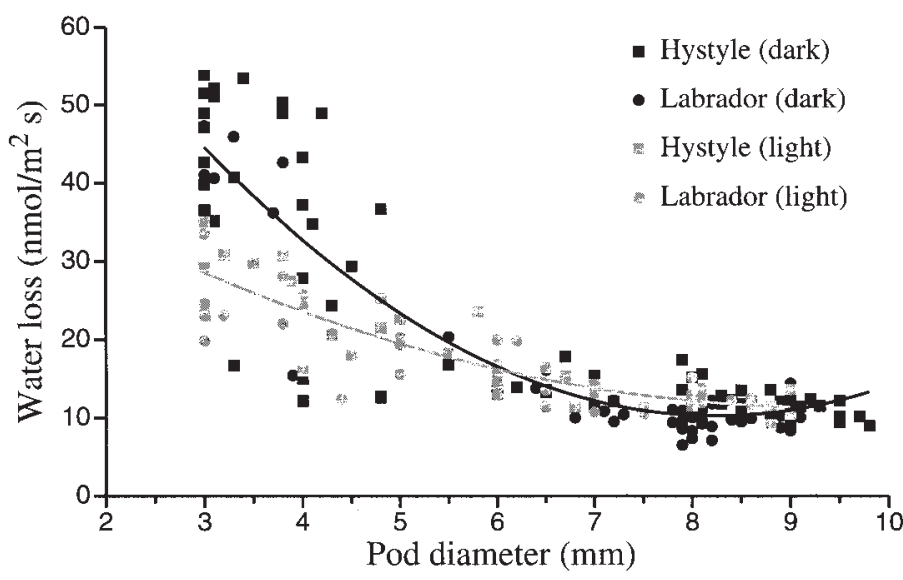

Fig. 3. Transpiration rates measured in pods of various diameters for two snap bean cultivars, Hystyle and Labrador. Transpiration was measured with an analytical balance as water loss from detached pods over a 1-h period; atmospheric conditions were $23{ }^{\circ} \mathrm{C}$ and $55 \%$ relative humidity. Data are presented for pods measured either in total darkness (dark) or in low illumination (light; a PPF of 40 $\left.\mu \mathrm{mol} \cdot \mathrm{m}^{-2} \cdot \mathrm{s}^{-1}\right)$. Polynomial regression equations were calculated for each data set; nearly identical curves were obtained for the two dark data sets, and for the two light data sets. Thus, for clarity, regressions were calculated and are presented for the combined dark data sets $\left(y=-0.12 \mathrm{x}^{3}+3.52 \mathrm{x}^{2}-34.21 \mathrm{x}+119.97, r^{2}=0.82\right)$ and the combined light data sets $\left(\mathrm{y}=0.049 \mathrm{x}^{3}-0.44 \mathrm{x}^{2}-3.08 \mathrm{x}+40.09, r^{2}=0.74\right)$. Plants were grown individually in pots in a greenhouse. Pod diameter was measured and stomatal density was determined at each pod's widest diameter.

the data to an analysis of variance showed significant effects for humidity treatments $(P<0.001)$ and cultivar type $(P<0.001)$ on pod $\mathrm{Ca}$ concentration. There was not a significant interaction between humidity and cultivar main effects $(P>0.28)$. Contrasts were used to compare the treatment effects on mean $\mathrm{Ca}$ concentration in each cultivar (Table 1). There was a significantly lower Ca concentration for pods in the high-RH treatment as compared to the control in both cultivars. There was not a significant increase in the Ca concentration of pods in the low-RH treatment; however, there was a trend for lowRH 'Hystyle' pods to display a higher Ca concentration than controls. In both cultivars, the $\mathrm{Ca}$ concentration of pods in the low- $\mathrm{RH}$ treatment was significantly higher than those in the high-RH treatment.

'Labrador' and 'Hystyle' pods under equivalent RH environments did not display equivalent pod $\mathrm{Ca}$ concentrations. 'Hystyle' pod Ca concentration was $45 \%$ greater than that of 'Labrador' in the high-RH treatment ( $t$ test, $P=0.003$ ), and $53 \%$ greater in the low-RH treatment ( $t$ test, $P=0.02$ ) (Table 1 ). Pod Ca concentration was $30 \%$ higher in pods from control 'Hystyle' plants as compared to 'Labrador' plants ( $t$ test, $P=0.02$ ).

\section{Discussion}

Pod ca concentrations. The concentration of $\mathrm{Ca}$ in developing pods declined with increasing pod diameter in all cultivars studied (Fig. 1). These results are generally consistent with previous reports that indicated an inverse relationship between pod Ca concentration and pod size or age (Mills and Jones, 1979; Mix and Marschner, 1976c; Quintana et al., 1996). However, this report is the first that correlates pod Ca concentration of individual pods with each pod's exact maximal diameter, and our measurements indicate that the slope of this inverse relationship varied significantly between certain cultivars (see Results; Fig. 1). This is at variance with the results reported by Quintana et al. (1996), that suggested an equivalent relationship for each of three cultivars, two of which were included in the present study. The results of Quintana et al. (1996) were obtained by measuring the average $\mathrm{Ca}$ concentration for combined pods of a given grade size and then plotting these values against a midpoint diameter for each grade size. The average diameter of the actual set of pods collected in each grade size fraction was not determined (as noted in their paper), and this lack of resolution apparently prevented them from observing the slope differences identified in the current study.

The inverse relationship between $\mathrm{Ca}$ concentration and pod diameter demonstrates that as a pod grows and matures, the transport of $\mathrm{Ca}$ to the pod does not keep pace with pod diameter or mass gain. Because the input of $\mathrm{Ca}$ to the pod will depend partially on the concentration of $\mathrm{Ca}$ in the xylem stream, this inverse relationship could be explained in part by the development-dependent reduction in root influx of Ca previously noted for two snap bean cultivars (Grusak et al., 1996). However, a developmental decline in total pod transpiration also would translate into a decline in $\mathrm{Ca}$ input to the pod. Thus, it is interesting to note the slope differences revealed in Fig. 1, because they indicate that in addition to differences in total $\mathrm{Ca}$ transport to the pods, development-dependent differences must exist between cultivars in the accretion of $\mathrm{Ca}$ by pods. One explanation for this would be that pod transpiration varies between cultivars.

Pod stomatal Densities. Pod stomatal density declined as pods matured for all cultivars, and differences in stomatal density were observed between cultivars with a given pod diameter (Fig. 2). Because stomates are generally involved in the facilitation of gas exchange, these results suggest that differences in pod transpiration might be observed developmentally for a given cultivar, as well as between cultivars.

The decline in stomatal density is apparently related to the expansive growth of the pod, such that as pod diameter increases, so will its surface area. It would appear either that the pod begins with a certain number of stomates and these become more diffuse as the pod expands, or that the rate of differentiation of nonspecialized epidermal cells into guard cells declines with increasing pod age. The fact that differences in slope were observed between cultivars in the relationship between stomatal density and pod diameter (Fig. 2) would suggest that there must be a differential recruitment of epidermal cells to guard cells between cultivars.

POD TRANSPIRATION RATE. If pod transpiration rates vary between cultivars, this would lead to differences in total water movement to pods of each cultivar, and differences in total Ca carried to those pods via xylem flow. Pod transpiration rates were measured either as water loss from detached pods (Fig. 3), or through the use of a porometer

Table 1. Calcium concentrations (dry mass basis) of mature snap bean pods that developed within enclosures in which relative humidity (RH) was maintained at a constant level for 'Labrador' and 'Hystyle'. Average RH values and calculated vapor pressure deficits (VPD) (pod to atmosphere) were as follows: high, $\mathrm{RH}=100 \%, \mathrm{VPD}=0 \mathrm{kPa}$; low, $\mathrm{RH}=15 \%, \mathrm{VPD}=2.36 \mathrm{kPa}$; control, $\mathrm{RH}=56 \%, \mathrm{VPD}=1.23 \mathrm{kPa}$.

\section{$\mathrm{Ca}\left(\mathrm{mg} \cdot \mathrm{g}^{-1}\right)$}

\begin{tabular}{lcc}
\hline Treatment & 'Labrador' & 'Hystyle' \\
\hline High RH & $2.9 \pm 0.2$ & $4.2 \pm 0.3$ \\
Low RH & $4.5 \pm 0.2$ & $6.9 \pm 0.9$ \\
Control (intermediate RH) & $4.2 \pm 0.2$ & $5.5 \pm 0.2$ \\
Contrasts & & \\
$\quad$ Control $\times$ high RH & $* *$ & $* *$ \\
$\quad$ Control $\times$ low RH & NS & NS \\
$\quad$ High RH $\times$ low RH & $* * *$ & $* * *$ \\
$\quad$ Control $\times$ high RH $\times$ low RH & $* * *$ & $* * *$
\end{tabular}

$\overline{\mathrm{Ns},{ }^{* *}, * * *}$ Nonsignificant or significant at $P<0.001$ or $0.0001, \pm \mathrm{se}, \mathrm{n} \geq 9$ pods between 8 and $9 \mathrm{~mm}$ in diameter selected from 6 plants. 
on small intact pods (see Results). These two measures were comparable for small pods, and thus the larger data set based on detached pods should be representative of the in planta condition.

Pod transpiration rates (measured under equivalent environmental conditions) were similar in 'Hystyle' and 'Labrador', which have high and low pod stomatal densities, respectively. Thus, in pods of equal diameter, a higher stomatal density does not elicit a higher rate of water loss. The rates measured in pods were roughly $10 \%$ to $20 \%$ of the rates measured in actively transpiring leaves, and were comparable to values of cuticular transpiration measured in leaves with closed stomates (Larcher, 1980). Cuticular water loss may therefore predominate in pods, thereby questioning the importance of pod stomatal density on the water relations of this organ. Stomatal frequency and function have similarly been shown to be reduced in a number of other fruiting organs (Altman et al., 1987; Esau, 1967; Glenn and Poovaiah, 1989; Lownds et al., 1993).

Although cultivar differences were not seen, it should be noted that transpiration rate did vary across pod diameters within a cultivar (Fig. 3), with higher rates measured for smaller diameter pods. This may have been due to differences in the degree of closure and/or composition of the cuticle (Kerstiens, 1996) in younger pods, rather than to differences in stomatal density, as noted above. It also is interesting that higher transpiration rates were measured with pods in darkness, relative to pods harvested and maintained in the light. As the light condition was an attempt to assess pods with potentially open stomates, the unexpectedly lower transpiration rates measured in these pods further suggests that stomates may not play a role, or may play only a limited role, in pod transpiration. In dry bean, reduced incorporation of atmospheric $\mathrm{CO}_{2}$ (only $5 \%$ on an area basis) in 3mm-diameter pods, relative to subtending leaves (Crookston et al., 1974), suggests that there may be a limited functioning of pod stomates, at least in smaller-diameter pods.

INFLUENCE OF POD MICROCLIMATE. Within each cultivar, higher$\mathrm{RH}$ microenvironments resulted in lower pod $\mathrm{Ca}$ concentrations (Table 1). This is as one would expect in that reductions in pod transpiration, due to a reduced water vapor gradient, would result in a reduction in the cumulative influx of xylem sap. However, equivalent RH treatments did not lead to equivalent pod Ca concentrations in the two cultivars. 'Hystyle' consistently exhibited higher pod $\mathrm{Ca}$ concentrations at all $\mathrm{RH}$ levels, even though transpiration rates were likely similar to those in 'Labrador'. Therefore, some factor or factors other than differential pod microenvironments must be responsible for the cultivar differences in pod Ca concentration. Because whole plant Ca uptake, as well as pod yield, were identical in 'Hystyle' and 'Labrador' (Grusak et al., 1996), the chamber results suggest that xylem sap delivered to 'Hystyle' pods contained a higher concentration of Ca.

IMPLICATIONS FOR ENHANCING POD CA CONCENTRATION. Although transpiration rates are low in developing pods of snap bean, pod transpiration is an important component of pod $\mathrm{Ca}$ nutrition, as it ensures Ca delivery to this organ. The pod enclosure studies showed that decreasing the water vapor gradient between pod and atmosphere leads to reduced rates of transpiration, reduced influx of xylem sap, and finally reduced accretion of $\mathrm{Ca}$. To enhance the $\mathrm{Ca}$ content of snap bean as a food source for humans, one might suggest that cultivars be developed whose pods are modified to enable higher rates of transpiration (possibly via cuticular transpiration), or at least to maintain the higher rates observed in younger pods (Fig. 3), as this would lead to increased cumulative influx of xylem sap and $\mathrm{Ca}$. This could be an option for cultivars destined for processing (freezing or canning); however, for fresh snap beans, a higher rate of pod transpiration probably would be detrimental to postharvest shelf life, as it could lead to accelerated dehydration. Consumer selection (or farmer harvest) of lower grade-size pods (i.e., narrower diameter) might be a more immediate way to enhance the dietary impact of snap bean with respect to $\mathrm{Ca}$, because narrower pods of all cultivars had higher Ca concentrations (Fig. 1).

\section{Literature Cited}

Abrams, S.A., M.A. Grusak, and J.E. Stuff. 1997. Calcium and magnesium absorption from vegetables and milk in children. FASEB J. 11:A573.

Altman, S.A., K.A. Corey, and W.R. Hruschka. 1987. Stomatal aperture determination of muskmelon fruits by microrelief image analysis. HortScience 22:629-631.

Clarkson, D.T. 1984. Calcium transport between tissues and its distribution in the plant. Plant Cell Environ. 7:449-456.

Cosgrove, D.J. 1986. Biophysical control of plant cell growth. Annu. Rev. Plant Physiol. 37:377-405.

Crookston, R.K., J. O'Toole, and J.L. Ozbun. 1974. Characterization of the bean pod as a photosynthetic organ. Crop Sci. 14:708-712.

Ehret, D.L. and L.C. Ho. 1986. Translocation of calcium in relation to tomato fruit growth. Ann. Bot. 58:679-688.

Esau, K. 1967. Plant anatomy. Wiley, New York.

Faust, M. and C.B. Shear. 1968. Corking disorders of apples: A physiological and biochemical review. Bot. Rev. 34:441-469.

Glenn, G.M. and B.W. Poovaiah. 1989. Cuticular properties and postharvest calcium applications influence cracking of sweet cherries. J. Amer. Soc. Hort. Sci. 114:781-788.

Grusak, M.A. 1994. Iron transport to developing ovules of Pisum sativum. I. Seed import characteristics and phloem iron-loading capacity of source regions. Plant Physiol. 104:649-655.

Grusak, M.A., B.W. Stephens, and D.J. Merhaut. 1996. Influence of wholeplant net calcium influx and partitioning on calcium concentration in snap bean pods. J. Amer. Soc. Hort. Sci. 121:656-659.

Hanger, B.C. 1979. The movement of calcium in plants. Commun. Soil Sci. Plant Anal. 10:171-193.

Kerstiens, G. 1996. Cuticular water permeability and its physiological significance. J. Expt. Bot. 47:1813-1832.

Larcher, W. 1980. Physiological plant ecology. Springer-Verlag, Berlin.

Lownds, N.K., M. Banaras, and P.W. Bosland. 1993. Relationships between postharvest water loss and physical properties of pepper fruit (Capsicum annuиm L.). HortScience 28:1182-1184.

Mills, H.A. and J.B. Jones, Jr. 1979. Elemental content of frozen snap bean fruit. HortScience 14:268-269.

Mix, G.P. and H. Marschner. 1976a. Calciumgehalte in Früchten von Paprika, Bohne, Quitte und Hagebutte im Verlauf des Fruchtwachstums (Calcium content in fruits of paprika, bean, quince and hip during fruit growth). Z. Pflanzenernaehr. 5:537-549.

Mix, G.P. and H. Marschner. 1976b. Calcium-Umlagerung in Bohnenfrüchten während des Samenwachstums (Redistribution of calcium in bean fruits during seed development). Z. Pflanzenphysiol. 80:354-366.

Mix, G.P. and H. Marschner. 1976c. Einflu $\beta$ exogener und endogener Faktoren auf den Calciumgehalt von Paprika- und Bohnenfrüchten (Effect of external and internal factors on the calcium content of paprika [pepper] and bean fruits). Z. Pflanzenernaehr. 5:551-563.

Nonami, H. and J.S. Boyer. 1987. Origin of growth-induced water potential. Solute concentration is low in apoplast of enlarging tissues. Plant Physiol. 83:596-601.

Quintana, J.M., H.C. Harrison, J. Nienhuis, J.P. Palta, and M.A. Grusak. 1996. Variation in calcium concentration among sixty $S_{1}$ families and four cultivars of snap bean (Phaseolus vulgaris L.). J. Amer. Soc. Hort. Sci. 121:789-793.

Raven, J.A. 1977. $\mathrm{H}^{+}$and $\mathrm{Ca}^{2+}$ in phloem and symplast: relation of relative immobility of the ions to the cytoplasmic nature of the transport paths. New Phytol. 79:465-480.

Shear, C.B. 1975. Calcium-related disorders of fruits and vegetables. HortScience 10:361-365.

U.S. Department of Agriculture. 1984. USDA agricultural handbook series 8. Composition of foods: Vegetables and vegetable products-Raw, processed, prepared. Nutrition Monitoring Div., Human Nutrition Info. Serv. USDA, Hyattsville, Md. 